\title{
Degradabilidade in situ do Farelo de Canola Tratado com Calor e/ou Tanino ${ }^{1}$ \\ Vânia Regina Loyola ${ }^{2}$, Geraldo Tadeu dos Santos ${ }^{3^{*}}$, Lúcia Maria Zeoula ${ }^{*}$, Vanderlei Bett ${ }^{4}$, André Luiz Taborianski Pereira ${ }^{5}$
}

\begin{abstract}
RESUMO - O objetivo deste trabalho foi avaliar a degradabilidade in situ do farelo de canola comercial tratado com água (controle), em autoclave a $127^{\circ} \mathrm{C}$ por $30 \mathrm{~min}$ (CC), com $15 \%$ de tanino de acácia negra (Acacia mearnsii) (CT) e tanino seguido de autoclavagem (CTC). O efeito destes tratamentos sobre a degradação in situ da matéria seca (MS) e proteína bruta (PB) foi avaliado pela técnica de saco de náilon, usando duas vacas da raça Holandesa fistuladas no rúmen. As estimativas de degradação efetiva, considerando a taxa de passagem de $5 \% / \mathrm{h}$, para a MS, foram 74,5; 64,2; 75,1; e 70,5\% nos tratamentos, controle, CC, CT e CTC e as de degradação efetiva da $\mathrm{PB}, 86,5 ; 64,0 ; 82,6 ;$ e 69,9\%, respectivamente. Não foi observado efeito do tratamento com tanino sobre a degradação da MS, no entanto, houve pequena influência sobre a degradação da PB. Os tratamentos (CC e CTC) reduziram a degradação da MS e PB. O efeito do aquecimento, aplicado após o tratamento com tanino, foi menor que seu efeito isolado, resultando em interação significativa. O tratamento com calor foi o mais efetivo na redução da degradação ruminal da MS e PB do farelo de canola.
\end{abstract}

Palavras-chave: degradabilidade, farelo de canola, proteína protegida, tanino

\section{In Situ Disappearance of Canola Meal Treated with Heat and/or Tannin}

\begin{abstract}
The objective of this work was to evaluate the in situ disappearance of canola meal treated with water (control), in autoclave at $127^{\circ} \mathrm{C}$ for $30 \mathrm{~min}$ (CC), with $15 \%$ of Acacia mearnsii tannin (CT) and tannin followed by autoclaving (CTC). The effect of these treatments on in situ disappearance of dry matter (DM) and crude protein (CP) was evaluated by the nylon bag technique, using two rumen fistulated Holstein cows. The estimates of effective degradation of DM for control, CC, CT and CTC were 74.5, 64.2, 75.1, and $70.5 \%$, and effective degradation of $\mathrm{CP}$ were $86.5,64.0,82.6$, and $69.9 \%$, respectively, assuming rumen of $5 \% / \mathrm{h}$ outflow rate. No effect of tannin treatment on DM degradation was reported, however, there was a small influence on CP degradation. The treatments (CC and CTC) reduced DM and CP degradation. The heating effect, after tannin treatment, was smaller than its isolated effect, resulting in significant interaction. The heat treatment was the most effective to reduce ruminal degradation of canola meal DM and CP.
\end{abstract}

Key Words: degradability, canola meal, protected protein, tannin

\section{Introdução}

O farelo de canola é um suplemento protéico com alto teor de proteína bruta ( $37 \%$ na MS), no entanto, grande parte de sua proteína é degradada no rúmen (de BOER et al., 1987), tornando o farelo de canola fonte relativamente pobre em proteína não-degradável (KHORASANI et al., 1989).

Entre os vários métodos propostos para diminuir a degradabilidade ruminal de proteínas de alto valor biológico, destacam-se o tratamento com calor, formaldeído e tanino (VARVIKKO et al., 1983; MOSHTAGHI NIA e INGALLS, 1992; e PACE et al., 1993). Esta estratégia visa atender as elevadas exigências de proteína não-degradável no rúmen de animais em alta produção (ØRSKOV, 1982).

$\mathrm{O}$ tratamento térmico tem sido largamente utilizado com o objetivo de diminuir a degradabilidade ruminal de fontes protéicas rapidamente degradáveis, como os farelos de canola e soja (MIR et al., 1984; McKINNON et al., 1991; e MOSHTAGHI NIA e INGALLS, 1992). A diminuição da degradabilidade da PB provocada pelo calor pode ser resultado da desnaturação da proteína e redução na sua solubilidade, o que favoreceria maior proporção de aminoácidos no intestino delgado (VAN SOEST, 1982). Em virtude de o farelo de canola já sofrer aquecimento úmido durante o processo de extração de óleo, o aquecimento

\footnotetext{
1 Parte da Dissertação apresentada à UEM, pelo primeiro autor, como um dos requisitos para obtenção do grau de Mestre em Zootecnia.

2 Zootecnista.

* Pesquisador - Bolsista do CNPq.

3 Professor do Departamento de Zootecnia - UEM-CCA-DZO.

4 Aluno do Mestrado em Zootecnia da UEM-CCA-DZO.

5 Aluno do Curso de Graduação em Zootecnia - Bolsista de Iniciação Científica - CNPq.
} 


\section{LOYOLA et al.}

adicional poderia ser um método simples para aumentar o valor deste farelo para animais em alta produção.

A pesquisa sobre o uso de taninos, como agente de proteção protéica, ainda é pouco desenvolvida. Alguns estudos de avaliação da proteção contra a degradação, realizados em in vitro, em líquido de rúmen, e de digestibilidade enzimática ainda não permitem evidenciar, conclusivamente, vantagem real (MÜHLBACH et al., 1982). Nesse sentido, PACE et al. (1993) observaram redução na degradabilidade ruminal in vitro da MS do farelo de soja tratado com tanino condensado. No entanto, RODRIGUES e LÓPES (1980) não obtiveram diferenças entre os efeitos do farelo de soja, tratado ou não com tanino condensado, sobre desempenho e balanço de nitrogênio de ovinos. MÜHLBACH et al. (1982) concluíram que, embora o tratamento do farelo de soja com tanino condensado tenha sido eficiente na proteção contra a desaminação, a reversão desta proteção pela ação enzimática não foi total, diminuindo, dessa forma, as vantagens obtidas com a redução da desaminação no rúmen. O nível de aplicação de tanino necessário à obtenção de proteção adequada, sem redução de sua disponibilidade intestinal, ainda não está definido e, provavelmente, depende do tipo de tanino empregado (condensado ou hidrolisável) e do tipo de proteína que será tratada.

Segundo DRIEDGER e HATFIELD (1972), a adição de tanino reduziu a desaminação do farelo de soja e o calor e/ou pressão da peletização podem favorecer as ligações entre tanino e proteína. No mesmo sentido, KHORASANI et al. (1989) submeteram o farelo de canola a aquecimento, após tratamento com ácido clorídrico, acético, fórmico ou propiônico, e concluíram que a redução na disponibilidade protéica não ocorreu unicamente em razão da ação dos ácidos. Da mesma forma, em virtude de o calor e o tanino exercerem ação protetora da fração protéica, possivelmente exista efeito interativo entre os tratamentos.

O objetivo deste trabalho foi avaliar a degradabilidade in situ da MS e PB do farelo de canola tratado com calor, tanino e a associação calor e tanino.

\section{Material e Métodos}

Duas vacas da raça Holandesa multíparas, em lactação, munidas de fístula ruminal, foram utilizadas neste experimento para estudo da degradabilidade in situ. A alimentação das vacas foi à base de ração total misturada, contendo $27 \mathrm{~kg}$ de silagem de milho,
$6 \mathrm{~kg}$ de ração concentrada (proporção de 55\% de volumoso e $45 \%$ de concentrado, com base na MS) e minerais, de acordo com o NRC (1989), conforme composição química apresentada na Tabela 2. O período de adaptação à alimentação experimental foi de 21 dias. Os animais foram alimentados três vezes ao dia $(8,13$ e $16 \mathrm{~h})$ e soltos em piquete para repouso, nos intervalos.

Os tratamentos utilizados no experimento foram:

C - farelo de canola (var. ICIOLA-41) tratado com água (controle);

CC - farelo de canola tratado com calor;

CT - farelo de canola tratado com $15 \%$ de tanino de acácia; e

CTC - farelo de canola tratado com $15 \%$ de tanino de acácia, seguido de tratamento térmico.

Para cada $100 \mathrm{~g}$ de farelo de canola controle, foram adicionados $100 \mathrm{~mL}$ de água destilada, sendo a mistura seca em estufa, a $55^{\circ} \mathrm{C}$, durante 48 horas. Ao tratamento com calor (CC), foi adicionado água destilada e, em seguida, a mistura foi colocada em bandejas de alumínio, disposta em camadas de $2 \mathrm{~cm}$, aquecida em autoclave, a $127^{\circ} \mathrm{C}$ por $30 \mathrm{~min}$ (pressão de $1,5 \mathrm{kgf} / \mathrm{cm}^{2}$ ), e secas a $55^{\circ} \mathrm{C}$, em estufa, durante 48 horas. O tratamento com tanino (CT) ocorreu da seguinte forma: $15 \mathrm{~g}$ de tanino de acácia foram diluídos em $100 \mathrm{~mL}$ de água destilada e adicionado a $100 \mathrm{~g}$ do substrato. Após aplicação, a mistura foi seca em estufa, a $55^{\circ} \mathrm{C}$, durante 48 horas. No tratamento com tanino e calor (CTC), o teor e a forma de aplicação do tanino foram os mesmos que CT; em seguida, a mistura foi aquecida da mesma forma que CC. Todos os tratamentos foram estocados em sacos plásticos. O extrato de acácia negra (Acacia mearnsii) (SETA LM-10) utilizado continha $71,2 \%$ de tanino na matéria natural $(\mathrm{MN})$. O teor de tanino de acácia negra (15\%) foi escolhido em função dos resultados obtidos por MÜHLBACH et al. (1982). Os teores de MS e PB do farelo de canola nos diferentes tratamentos estão apresentados na Tabela 1.

A degradabilidade da MS e PB do farelo de canola foi estimada pela técnica in situ de saco de náilon. Os sacos lacrados a quente, feitos de náilon (ANKOM-Technology Co., Fairport, NY14450-USA), de dimensão $5 \times 7 \mathrm{~cm}$, com poros de aproximadamente $53 \mu \mathrm{m}$, foram utilizados para incubação ruminal. As amostras foram moídas em peneira de $2 \mathrm{~mm}$, e aproximadamente $2 \mathrm{~g}$ de amostra (base $\mathrm{MN}$ ) foram colocados em cada um dos sacos, que foram fechados e atados com fios de náilon de $15 \mathrm{~cm}$ de comprimento. Os sacos, em duplicatas, para cada animal, 
600 Rev. bras. zootec.

Tabela 1 - Composição do farelo de canola tratado com calor e/ou tanino

Table 1 - Composition of canola meal treated with heat and/or tannin

\begin{tabular}{lcc}
\hline $\begin{array}{l}\text { Tratamento } \\
\text { Treatment }\end{array}$ & MS $(\%)$ & PB $(\% \mathrm{MS})$ \\
\hline $\begin{array}{l}\text { Farelo não-tratado } \\
\text { Meal not treated }\end{array}$ & 89 & 37,9 \\
C $^{1}$ & 99,0 & \\
CC & 91,4 & 42,5 \\
CT & 93,0 & 40,9 \\
CTC & 92,3 & 35,6 \\
${ }^{1}$ C=farelo de canola controle tratado com água (canola meal control \\
treated with water), CC=farelo tratado com calor (canola meal treated \\
with heat), CT=farelo tratado com tanino (canola meal treated with \\
tannin), e CTC=farelo tratado com tanino e calor (canola meal treated \\
with heat and tannin).
\end{tabular}

foram presos a uma barra cilíndrica de ferro inox de $540 \mathrm{~g}$. Durante a incubação, a barra foi presa à cânula por um fio de náilon de $60 \mathrm{~cm}$. Os tempos de incubação foram 3, 6, 9, 24 e 48 horas, com todos os sacos retirados do rúmen ao mesmo tempo. Após a remoção, os sacos foram lavados à máquina por 4 ciclos de 10 min com troca de água, juntamente com os sacos representando o tempo $0 \mathrm{~h}$. Após a lavagem, todos os sacos foram secos em estufa, com ar forçado, a $55^{\circ} \mathrm{C}$, por 72 horas. A porcentagem de degradação da MS e PB, em cada tempo, foi calculada pela proporção de alimento que permaneceu nos sacos, não sendo corrigida para contaminação bacteriana. A degradação da MS e PB foram calculadas utilizando-se a equação descrita por MEHERZ e ØRSKOV (1977):

$$
\mathrm{p}=\mathrm{a}+\mathrm{b}\left(1-\mathrm{e}^{-\mathrm{ct}}\right)
$$

em que $\mathrm{p}$ é taxa de degradação no tempo t; a, fração de MS ou PB que é prontamente degradável no rúmen; $b$, fração da MS ou $\mathrm{PB}$ que é potencial- mente degradável; c, taxa constante de degradação da fração b; e t, tempo de incubação.

Os parâmetros não-lineares $a, b$ e c foram estimados por meio de procedimentos iterativos de quadrados mínimos (iterative least-squares procedures) (SAS, 1985). A degradabilidade efetiva da MS (DEMS) e PB (DEPB) no rúmen foram calculadas usando a seguinte equação de $\varnothing \mathrm{RSKOV}$ e McDONALD (1979):

DEMS ou DEPB $=\mathrm{a}+(\mathrm{b} \times \mathrm{c} / \mathrm{c}+\mathrm{k})$

em que ké taxa estimada de passagem dos sólidos no rúmen; os demais parâmetros já foram descritos acima.

A degradação efetiva da MS e PB foi estimada para cada tratamento, assumindo-se a taxa de passagem no rúmen de $5 \% / \mathrm{h}$, atribuída ao nível de ingestão médio (ARC, 1984).

Amostras dos tratamentos e dos respectivos resíduos dos sacos foram analisadas para matéria seca e proteína bruta $(\mathrm{N} \times$ 6,25) pelo método Kjeldahl (AOAC, 1980).

Os valores observados de degradação da MS e PB foram submetidos à ANOVA, de acordo com delineamento inteiramente casualizado em arranjo fatorial $2 \times 2$, sendo dois níveis de calor (ausência e presença) e dois níveis de tanino (ausência e presença), utilizando-se o GLM do SAS (1985). As vacas foram consideradas como repetições.

O modelo estatístico para análise dos dados foi:

em que

$$
\mathrm{y}_{\mathrm{ijk}}=\mu+\alpha_{\mathrm{i}}+\beta_{\mathrm{j}}+(\alpha \beta)_{\mathrm{ij}}+\mathrm{E}_{(\mathrm{ij}) \mathrm{k}}
$$

$\mathrm{y}_{i j k}$ é observação referente à repetição $k$, que recebeu o nível de calor $i$ com o nível de tanino $j ; \mu$, constante geral; $\mathrm{a}_{i}$, efeito do nível de calor $i$ (presença ou ausência); $\beta_{j}$, efeito do nível de tanino $j$ (presença ou ausência); $(\alpha \beta)_{i j}$, efeito da interação entre o nível

Tabela 2 - Composição química da alimentação das vacas fistuladas (\% MS)

Table 2 - Composition of diets in the fistulated cows feeding (\%DM)

\begin{tabular}{lcc}
\hline $\begin{array}{l}\text { Nutriente } \\
\text { Ingredient }\end{array}$ & $\begin{array}{c}\text { Raçãoconcentrada } \\
\text { Concentrate diet }\end{array}$ & $\begin{array}{c}\text { Silagem de milho } \\
\text { Corn silage }\end{array}$ \\
\hline $\begin{array}{l}\text { Matéria seca (\%) } \\
\text { Dry matter }\end{array}$ & 89,0 & 27,6 \\
$\begin{array}{l}\text { Matéria orgânica (\%) } \\
\text { Organic matter }\end{array}$ & 93,6 & 94,5 \\
$\begin{array}{l}\text { Proteína bruta (\%) } \\
\text { Crude protein }\end{array}$ & 26,1 & 6,1 \\
$\begin{array}{l}\text { Fibra em detergente ácido (FDA) (\%) } \\
\text { Acid detergent fiber }(A D F)\end{array}$ & 6,6 & 40,4 \\
$\begin{array}{l}\text { Fibra em detergente neutro (\%) } \\
\text { Neutral detergent fiber }(N D F)\end{array}$ & 5,7 & 65,5 \\
\hline Ração concentrada contem $(c o n$ &
\end{tabular}

${ }^{1}$ Ração concentrada contém (concentrate diet): $27,47 \%$ de farelo de soja (soybean meal); $6,87 \%$ farelo de canola (canola meal); $3,85 \%$ farinha de carne (meat meal); $14,9 \%$ farelo de trigo (wheat meal); $45,82 \%$ de milho moído (ground corn grain); $1 \%$ de sal mineral (mineral mixture). 
de calor $i$ e nível de tanino $j$; e $\mathrm{E}_{(i j) k}$, erro aleatório associado a cada observação $k$, que recebeu a combinação nível $i$ de calor e nível $j$ de tanino.

\section{Resultados e Discussão}

As estimativas não-lineares e a degradabilidade efetiva do farelo de canola tratado com calor e/ou tanino são apresentadas na Tabela 3.

Aproximadamente $57 \%$ da MS e $63 \%$ da PB (a) do farelo de canola controle (C) desapareceram quase imediatamente do rúmen. A taxa de degradação (c) da MS e PB deste mesmo tratamento foi de 17,6 e 19,5\% e as frações sujeitas à degradação (b), 25,9 e 31,1\%, respectivamente. A degradabilidade efetiva da MS (DEMS) e a DE da PB (DEPB) foram 74,6 e 86,5\%, respectivamente, para taxa de passagem de $5 \% / \mathrm{h}$.

Os valores de DEMS e DEPB para o farelo de canola controle, encontrados no presente trabalho, aproximam-se dos relatados por BAILEY e HIRONAKA (1984). No entanto, as estimativas de a, b, c, DEMS e DEPB diferem das encontradas por KIRKPATRICK e KENNELLY (1987) e KENDALL et al. (1991), para farelo de canola.

Fatores que parecem influenciar as estimativas de degradabilidade incluem diferenças entre processos de manufatura do farelo de canola (KENDALL et al., 1991) e nível de concentrado (PETIT, 1992) e de PB (KIRKPATRICK e KENNELLY, 1987) nas dietas consumidas pelos animais fistulados utilizados nas incubações in situ. Constatou-se que os animais deste trabalho receberam maior proporção de volumoso que concentrado: 55 e $45 \%$, respectivamente, e que aumento na quantidade de volumoso está associado a incremento na degradação protéica da dieta pelos microrganismos ruminais ( $\varnothing \mathrm{RSKOV}, 1982)$. Os altos valores da fração solúvel obtidos para o farelo de canola, comparados com os de autores citados, podem ser conseqüência das finas partículas produzidas após a secagem do farelo, sendo que, no procedimento in situ, estão prontamente disponíveis aos microrganismos ruminais ou perdas de partículas no processo de lavagem dos sacos (HUNTINGTON e GIVENS, 1997).

As frações solúveis da MS e PB do farelo de canola sofreram redução $(\mathrm{P} \leq 0,05)$ sob ação do tratamento com calor. O tratamento com tanino não teve efeito sobre estas frações, e a associação tanino-calor reduziu $(\mathrm{P} \leq 0,05)$ apenas a fração solúvel da $\mathrm{PB}$, porém, em menor intensidade que o tratamento com calor. A taxa de degradação da fração b da MS e PB foi influenciada

Tabela 3 -Média dos quadrados mínimos para estimativas não-lineares e degradação efetiva do farelo de canola tratado com calor elou tanino

Table 3 - Least squares means for the non linear estimation and efective degradation of canola meal treated with heat and/or tannin

\begin{tabular}{|c|c|c|c|c|c|c|c|c|}
\hline \multirow[b]{2}{*}{ Item $^{2}$} & \multicolumn{4}{|c|}{$\begin{array}{c}\text { Farelo de canola } \\
\text { Canola meal }\end{array}$} & \multirow[b]{2}{*}{$\mathrm{EP}^{1}$} & \multicolumn{3}{|c|}{$\begin{array}{l}\text { Probabilidade } \\
\text { Probability }\end{array}$} \\
\hline & $\mathrm{C}$ & $\mathrm{CC}$ & $\mathrm{CT}$ & CTC & & $\begin{array}{l}\text { Calor } \\
\text { Heat }\end{array}$ & $\begin{array}{l}\text { Tanino } \\
\text { Tannin }\end{array}$ & $*$ \\
\hline \multicolumn{9}{|l|}{$\overline{\mathrm{MS}(D M)}$} \\
\hline $\mathrm{a}$ & $56,8 \mathrm{a}$ & $39,4 \mathrm{~b}$ & $60,1 \mathrm{a}$ & $57,6 a$ & 3,2 & 0,0154 & 0,0116 & 0,0384 \\
\hline$b$ & $25,9 b$ & $44,0 \mathrm{a}$ & $23,9 b$ & $25,6 b$ & 3,2 & 0,0132 & 0,0118 & 0,0250 \\
\hline $\mathrm{c}$ & 17,6 & 8,3 & 20,3 & 5,1 & 2,5 & 0,0046 & 0,8980 & 0,2408 \\
\hline $\begin{array}{l}\text { DEMS }(E D D M) \\
\mathrm{PB}(C P)\end{array}$ & $74,6 \mathrm{a}$ & $64,2 \mathrm{c}$ & $75,1 \mathrm{a}$ & $70,5 b$ & 1,7 & 0,0001 & 0,0026 & 0,0047 \\
\hline $\mathrm{a}$ & $63,3 a$ & $27,9 \mathrm{c}$ & $63,7 \mathrm{a}$ & $53,1 b$ & 5,6 & 0,0005 & 0,0040 & 0,0058 \\
\hline$b$ & $31,1 b$ & $66,8 \mathrm{a}$ & $30,3 b$ & $37,4 b$ & 5,7 & 0,0005 & 0,0018 & 0,0022 \\
\hline $\mathrm{c}$ & 19,5 & 7,7 & 19,2 & 4,2 & 2,9 & 0,0194 & 0,6217 & 0,6807 \\
\hline $\operatorname{DEPB}(E D C P)$ & $86,5 \mathrm{a}$ & $64,0 \mathrm{~d}$ & $82,6 b$ & $69,9 \mathrm{c}$ & 3,5 & 0,0001 & 0,3263 & 0,0055 \\
\hline
\end{tabular}

Médias, na linha, com letras diferentes são diferentes $(P \leq 0,05)$ pelo teste Tukey.

${ }^{1}$ Erro-padrão das médias dos quadrados mínimos ( $\mathrm{n}=$ dois animais por tratamento).

$2 \mathrm{a}=$ porção (porcentagem) de material (MS, PB) que desaparece no início da incubação; $b=$ fração (porcentagem) de MS e PB potencialmente degradável no rúmen; $c=$ taxa constante (porcentagem por hora) de degradação da fração b; DEMS = degradabilidade efetiva da MS; DEPB $=$ degradabilidade efetiva da proteína bruta; e $\mathrm{k}=5 \% / \mathrm{h}$ de taxa de passagem.

* Interação entre calor e tanino (Interaction between heat and tannin).

Means, within a row, followed by different letters are different $(P \leq .05)$ by Tukey test.

${ }^{1}$ Standard error of mean squares ( $n=$ two cows per treatment).

$2 a=$ fraction (percentage) of material (DM and CP) that disappear in the beggining of incubation; $b=$ fraction (percentage) of material (DM and CP) potentially degradable in the rumen; $c$ = constant rate (percentage per hour) of fraction $b$ degradation; EDDM = fraction effective degradability of $D M$; EDCP = fraction effective degradability of $C P ; k=$ rate of passage $=5 \% / h$. 
602 Rev. bras. zootec.

apenas pelo efeito do aquecimento.

De acordo com LEHNINGER (1976), a exposição de proteínas a altas temperaturas ou extremos de $\mathrm{pH}$ causa sua desnaturação, devido à ruptura das pontes de hidrogênio, resultando em alteração da estrutura terciária da proteína. O maior efeito da desnaturação é o decréscimo da solubilidade protéica em soluções aquosas (AAR et al., 1984), como constatado pelos resultados deste trabalho. O mecanismo de proteção por tratamento térmico envolve, principalmente, a reação de Maillard (HURREL e FINOT, 1985), cujos primeiros estádios (aldosilaminas e bases de Schiff) são caracterizados por ligações resistentes à ação enzimática (Schroeder et al., 1955, citados por MOSIMANYANA e MOWAT, 1992). Dessa forma, o tratamento térmico reduz a degradação ruminal, parcialmente, por bloquear os sítios reativos para enzimas proteolíticas microbianas e reduzir a solubilidade protéica (BRODERICK e CRAIG, 1980; WALTZ e LOERCH, 1986). O tratamento térmico reduz a taxa de degradação e a fração solúvel e aumenta a fração potencialmente degradável (VANHATALO et al., 1995), o que está de acordo com os resultados obtidos pelo presente trabalho.

A redução da degradabilidade da MS e PB, como conseqüência do tratamento térmico, tem sido observada em outros trabalhos utilizando farelo ou semente de canola (MIR et al., 1984; McKINNON et al., 1991; e MOSHTAGHI NIA e INGALLS, 1992). A redução na DEPB de $26,0 \%$, comparada ao controle, encontrada neste trabalho, é semelhante aos resultados de McKINNON et al. (1991), que relataram diminuição em relação ao farelo de canola não-tratado, de $27 \%$ na proteína degradável do farelo aquecido a $125^{\circ} \mathrm{C}$, por 30 min. Da mesma forma, MOSHTAGHINIA e INGALLS (1992) observaram redução na degradabilidaderuminal da $\mathrm{PB}$ do farelo de canola autoclavado, a $127^{\circ} \mathrm{C}$ por $30 \mathrm{~min}$, comparado ao controle, de 53\%. Da mesma forma, MIR et al. (1984) verificaram decréscimo bem menor $(6,6 \%)$ na degradabilidade da PB do farelo de canola, comparado ao controle, como conseqüência do aquecimento a $120^{\circ} \mathrm{C}$, por $20 \mathrm{~min}$.

Por outro lado, os taninos se ligam às proteínas por interação de seus grupos hidroxila reativos com grupos carbonila das proteínas. Pontes de hidrogênio e interações hidrofóbicas parecem ser as principais ligações envolvidas na formação dos complexos tanino-proteína (ARTZ et al., 1987), sendo as pontes de hidrogênio mais dependentes $\mathrm{pH}$ que as interações hidrofóbicas. Os taninos condensados diminuem a utilização protéica por interação com a proteína, formando complexos indigestíveis; por inativação das enzimas proteolíticas; por interferência com o muco epitelial protetivo do intestino; ou por alteração na absorção dos nutrientes digeridos (Oh e Hoff, 1986, citados por ALZUETA et al., 1992). Os taninos podem inibir o processo de adesão/ataque microbiano às partículas alimentares (MAKKAR et al., 1988).

Os resultados pouco expressivos, obtidos para o tratamento com tanino, discordam dos relatos de DRIEDGER e HATFIELD (1972), em que a adição de $10 \%$ de tanino reduziu em $90 \%$ a deaminação do farelo de soja. Da mesma forma, a avaliação do tanino de acácia negra, feita por MÜHLBACH et al. (1982), demonstrou efetividade na proteção da proteína do farelo de soja, em estudos de digestão in vitro. PACE et al. (1993) concluíram que $20 \%$ de tanino condensado provocaram diminuição na degradabilidade ruminal in vitro da MS do farelo de soja. No entanto, a reação entre taninos e proteínas depende da configuração espacial das moléculas e disponibilidade dos grupos fenólicos reativos (Pierpoint, 1983 citado por MANGAN, 1988), portanto, diferentes proteínas possuem diferentes afinidades por taninos (Hagerman e Butler, 1978 citados por MANGAN, 1988). Existe a possibilidade de que o teor testado de tanino condensado não tenha sido suficiente para atingir o mesmo grau de proteção, obtido por outros autores, para o farelo de soja.

$\mathrm{O}$ efeito isolado do calor (CC), comparado ao controle, reduziu $(\mathrm{P} \leq 0,05)$ a DEMS em $13,9 \%$ e a DEPB em 26,0\%, enquanto, em presença de tanino (CTC), a redução $(\mathrm{P} \leq 0,05)$ foi de $5,5 \%$ para DEMS e $19,2 \%$ para DEPB. O tanino (CT) não produziu efeito $(\mathrm{P}>0,05)$ sobre a DEMS e acarretou decréscimo de apenas $4,5 \%$ para DEPB, comparado ao controle. Verifica-se que o tratamento com calor, quando associado ao tanino, promoveu menor redução na degradabilidade do farelo de canola, o que explica o efeito interativo entre os fatores. Estes resultados discordam da suposição de DRIEDGER e HATFIELD (1972) de que o calor e/ou pressão da peletização podem favorecer as ligações entre tanino e a proteína do farelo de soja. A presença do tanino pode ter impedido a formação dos complexos proteína-carboidrato (reação de Maillard) durante o aquecimento, como ocorreu no tratamento exclusivo com calor. Neste caso, a reatividade e solubilidade do tanino podem ter sofrido alteração após o aquecimento (KADAM et al., 1987).

A hipótese de que o desempenho de vacas leiteiras em alta produção e ruminantes em crescimento 
pode ser incrementado pela redução da degradabilidade protéica no rúmen (ARC, 1984; NRC, 1989) não foi confirmada por alguns autores, não sendo encontrada evidência em experimentos com animais (RODRIGUES e LÓPES, 1980, ONYANGO e INGALLS, 1994). Portanto, tem-se enfatizado (NRC, 1989) que, somados aos dados obtidos em estudos utilizando sacos de náilon, dados de resposta produtiva são necessários para se verificar o efeito do tratamento sobre o valor nutritivo da proteína alimentar para ruminantes.

\section{Conclusões}

Entre os tratamentos testados, o tratamento com calor foi o mais efetivo em reduzir a degradação ruminal da MS e PB do farelo de canola. O tratamento com tanino de acácia negra não teve efeito sobre a degradabilidade da MS e causou leve redução na degradabilidade da PB. O tratamento que associou tanino e calor acarretou redução intermediária na degradação da MS e PB. Concluiu-se que a associação dos tratamentos não propiciou aumento na ação protetora, ao contrário, a ação do calor foi prejudicada devido à influência do tanino.

\section{Referências Bibliográficas}

AGRICULTURAL RESEARCH COUNCIL - ARC. 1984. The nutrient requirements of ruminant livestock. Commonwealth Agricultural Bureaux, Farham Royal, U. K.

ALZUETA, C., TREVIÑO, J., ORTIZ, L. 1992. Effect of tannins from faba bean on protein utilisation in rats. J. Sci. Food Agric., 59:551-553.

ARTZ, W.E., BISHOP, P.D., DUNKER, A.K. et al. 1987. Interactions of synthetic proanthocyanidin dimer and trimer with bovine serum albumin and purified bean globulin fraction G-1. J. Agric. Food Chem., 35:417-421.

ASSOCIATION OF OFFICIAL ANALYTICAL CHEMISTS AOAC. 1980. Official methods of analysis. 14. ed. AOAC, Arlington, VA.

BAILEY, C.B., HIRONAKA, R. 1984. Estimation of the rumen degradability of nitrogen and of nonprotein organic matter in formaldehyde-treated and untreated canola meal. Can. J. Anim. Sci., 64:183-185.

BRODERICK, G. A., CRAIG, W. M. 1980. Effect of heat treatment on ruminal degradation and escape, and intestinal digestibility of cottonseed meal protein. J. Nutr., 110:2381-2389.

de BOER, G., MURPHY, J.J., KENNELLY, J.J. 1987. Mobile nylon bag for estimating intestinal availability of rumen undegraded protein. J. Dairy Sci., 70(5):977-982.

DRIEDGER, A., HATFIELD, E.E. 1972. Influence of tannins on the nutritive value of soybean meal for ruminants. J. Anim. Sci., 34:465-468.

HUNTINGTON, J.A., GIVENS, D.I. 1997. Studies on in situ degradation of feeds in the rumen: 1. Effect of species, bag motility and incubation sequence on dry matter disappearance. Anim. Feed Sci. and Techn., 64:227-241.

HURREL, R.F., FINOT, R.A. 1985. Effect of food processing on protein digestibility and amino acid availability. In: Digestibility and amino acid availability in cereals and oilseeds. FINLEY, J. W. , HOPKINS, D. T. (Eds.) American association of Cereal Chemists, St. Paul, Minn, p.233-258.

KADAM, S.S., SMITHARD, R.R., EYRE, M.D. et. al. 1987. Effects of heat treatments of antinutritional factors and quality of proteins in winged bean. J. Sci. Food Agric., 39:267-275.

KENDALL, E.M., INGALLS, J.R., BOILA, R.J. 1991. Variability in the rumen degradability and postruminal digestion of the dry matter, nitrogen and amino acids of canola meal. Can. J. Anim. Sci., 71:739-754.

KHORASANI, G.R., ROBINSON, P.H., KENNELLY, J.J. 1989. Effect of chemical treatment on in vitro and in situ degradation of canola meal crude protein. J. Dairy Sci., 72:2074-2080.

KIRKPATRICK, B.K., KENNELLY, J.J. 1987. In situ degradability of protein and dry matter from single protein sources and from a total diet. J. Anim. Sci., 65:567-576.

LEHNINGER, A.L. 1976. Biochemistry. New York: Worth Publishers Inc. $833 \mathrm{p}$.

MAKKAR, H.P.S., SINGH, B., DAWRA, R.K. 1988. Effect of tannin-rich leaves of oak (Quercus incana) on various microbial enzyme activities of the bovine rumen. Br. J. Nutr., 60:287296.

MANGAN, J.L. 1988. Nutritional effects of tannins in animal feeds. Nutr. Research Rev., 1:209-231.

MEHREZ, A.Z., ØRSKOV, E.R. 1977. A study of the artificial fiber bag technique for determining the digestibility of feeds in the rumen. J. Agric. Sci., 88:645-650.

McKINNON, J.J., OLUBOBOKUN, J.A., CHRISTENSEN, D.A. et al. 1991. The influence of heat and chemical treatment on ruminal disappearance of canola meal. Can. J. Anim. Sci., 71:773-780.

MIR, Z., MacKEOD, G.K., BUCHANAN-SMITH, J.G. et al. 1984. Methods for protecting soybean and canola proteins from degradation in the rumen. Can.J. Anim. Sci., 64:853-865.

MOSHTAGHI NIA, S.A., INGALLS, J.R. 1992. Effect of heating on canola meal protein degradation in the rumen and digestion in the lower gastrointestinal tract of steers. Can. J. Anim. Sci., 72:83-88.

MOSIMANYANA, B.M., MOWAT, D.N. 1992. Rumen protection of heat-treated soybean proteins. Can. J. Anim. Sci., 72:71-81.

MÜHLBACH, P.R.F., LÓPEZ, J., LEBOUT, E.M. 1982. Avaliação in vitro dos taninos de castanheira (Castanea sativa Mill.) e acácia negra (Acacia mearnsii De Willd.) como agentes de proteção da proteção da proteína do farelo de soja. R. Soc. Bras. Zootec., 11(4):746-762.

NATIONAL RESEARCH COUNCIL - NRC. 1989. Nutrient requirements of dairy cattle. 6 . ed. Washington, DC.: National Academy Press.

ONYANGO, T.A., INGALLS, J.R. 1994. Feed intake and lactation response of cows fed heat treated canola meal and high undegradable protein supplements in early lactation. $J$. Anim. Sci., 72:237 (Suppl. 1).

$\varnothing$ RSKOV, E.R. 1982. Protein nutrition in ruminants. New York: Academic Press. p.125-129.

$\varnothing$ RSKOV, E.R., McDONALD, I. 1979. The estimation of protein degradability in the rumen from incubation measurements weighted according to rate of passage. J. Agric. Sci., 92:499-503.

PACE, V., SETTINERI, D., CATILLO, G. 1993. Influenza di trattamenti con tannini sulla digeribilità in vitro della farina di soia. Zoot. Nutr. Anim., 19:73-79. 
604 Rev. bras. zootec.

PETIT, H.V. 1992. In situ degradability of feed ingredients at two proportions of concentrate. Ann. Zootech., 41:145-152.

RODRIGUES, C.O., LÓPEZ, J. 1980. Efeito do pré-tratamento com tanino na utilização da proteína pelos ovinos. $R$. Soc. Bras. Zootec., 9(3):373-387.

STATISTICAL ANALYSIS SYSTEM INSTITUTE. 1985. SAS user's guide: Statistics. 5 ed., Cary, NC.

van der AAR, P. J., BEGER, L. L., FAHEY, JR. et al. 1984. Effect of alcohol treatment of soybean meal on ruminal escape of soybean meal protein. J. Anim. Sci., 59:483-489.

VANHATALO, A., ARONEN, I., VARVIKKO, T. 1995. Intestinal nitrogen digestibility of heat-moisture treated rapeseed meals as assessed by the mobile-bag method in cows. Anim. Feed Sci. and Technol., 55:139-152.

VAN SOEST, P.J. 1982. Nitrogen metabolism. In: Nutritional ecology of the ruminant. Corvallis, OR: O \& B Books Inc. p.232-233.
VARVIKKO, T., LINDBERG, J.E., SETALA, J. et al. 1983. The effect of formaldehyde treatment of soya-bean meal and rapeseed meal on the amino acid profiles and acid-pepsin solubility of rumen undegraded protein. J. Agric. Sci., 101:603-612.

WALTZ, D. M., LOERCH, S. C. 1986. Effect of acid and alkali treatment of soybean meal on nitrogen utilization by ruminants. J. Anim. Sci., 63:879-887.

Recebido em: $24 / 06 / 97$

Aceito em: 04/12/98 